\title{
Long term immersion in natural seawater of Flax/PLA biocomposite
}

\author{
A. Le Duigou ${ }^{a,{ }^{*}}$, A. Bourmaud ${ }^{a}$, P. Davies ${ }^{b}$, C. Baley ${ }^{a}$
}

\begin{abstract}
a LIMATB, Laboratoire d'Ingénierie des matériaux de Bretagne, Equipe Polymères et Composites, Rue de Saint Maudé BP 92116, 56321 Lorient, France

${ }^{\mathrm{b}}$ IFREMER, Marine Structures Group, Brest Centre, BP70, 29280 Plouzané, France
\end{abstract}

\author{
*: Corresponding author: A. Le Duigou, tel.: +33 297874586 ; fax: +33 297874588 ; \\ email address : Antoine.le-duigou@univ-ubs.fr
}

Alain.bourmaud@univ-ubs.fr ; peter.davies@ifremer.fr ; $\underline{\text { Christophe.baley@univ-ubs.fr }}$

\begin{abstract}
:
Innovation in sailing yacht design must include current environmental concerns such as resource depletion and waste management. Indeed most of the materials used today are petro-based and cannot offer viable end of life treatment. Fully biodegradable natural fibre reinforced biopolymers are being increasingly studied as they offer high specific stiffness and low environmental footprint. However, their ageing mechanisms are still not well understood.

The present article gives information on 2 years natural seawater aging effect on injection-molded Flax/PLA biocomposite. Biocomposites suffer from relatively high moisture absorption which is controlled by the vegetal fibres. Simple rules of mixtures allow the determination of weight gain for flax fibres which is around $12 \%$. Bundles of fibres and especially middle lamellae influence water uptake. Water alters flax fibres and their biocomposites, since their mechanical properties (Young's modulus and tensile strength) are reduced with aging. A linear relationship is observed between water uptake and loss of mechanical properties. Load-unload cycles highlight damage occuring earlier than unaged biocomposites. This damage can be induced by fibre degradation and washing out of soluble components especially the fibre bundles cement, and by debonding of fibre bundles linked to their swelling.
\end{abstract}

\section{Highlights}

2 Years seawater aging effect on injected Flax/PLA biocomposites is studied. Biocomposite suffer from relatively high moisture absorption. Biocomposites mechanical properties are linearly reduced with aging. Damages can be induced by fibre degradation and washing out of soluble components. 


\section{List of abbreviations}

- $\Delta W$, water uptake at saturation;

- $D$, Fickian diffusion coefficient;

- $D_{c}$, Fickian corrected diffusion coefficient;

- $E_{f L}$, longitudinal fibre modulus;

- $E_{f T}$, transverse fibre modulus;

- $E_{F}$, longitudinal composite modulus;

- $E_{T}$, transverse composite modulus

Keywords : Natural fibre composites ; Seawater ageing ; Damage mechanism 


\section{Introduction}

Development within the marine industry, and for sailing yachts in particular, have been accompanied by widespread use of composite material. However according to the FIN (French industrial marine federation) around 20000 boats reach the end of their life in 2015 while $95 \%$ of them are manufactured with glass reinforced unsaturated polyester resin composites (Boniou and Trémaré, 2006). However according Annette Roux (President of the French boatbuilding federation FIN and the main shareholder of Groupe Beneteau) has stated that the industry has worked hard on techniques to destroy old fibreglass hulls, instead of having owners abandon them. "But so far we are having difficulty finding any: they are in good condition and sailors continue to use them" (Roux). Whatever the composites boat real lifetime, design option should be developed to facilitate future waste management.

Glass fibre/Polypropylene thermoplastic matrix composites which can be recycled at end of life are gaining attention. Biocomposites (plant fibres embedded in a biopolymer matrix) possess a large number of advantages and can substitute traditional composites materials. First, they come from renewable resources, have high specific mechanical properties (Bodros et al., 2007; Le Duigou et al., 2010; Oksman et al., 2003; Plackett et al., 2003; Roussière et al., 2011) and in particular a high stiffness to density ratio, which can bring benefits in light and stiff leisure yacht design, based on the ISO 12215-5 standard. In addition these materials make possible waste management by recycling (Le Duigou et al., 2008) or composting (Kumar et al., 2010). Overall, the use of biocomposites such as Flax/Polylactide induces an environmental footprint reduction compared to Glass/Polyester (Le Duigou et al., 2012b).

However the lifetime span of Flax/PLA biocomposites has an influence on environmental impact (Le Duigou et al., 2012b). The closer the lifetime is to usetime, the more the impact is reduced. Therefore increasing use of biocomposite for outdoor applications depends on how the degradation mechanism is understood and handled. The marine environment is known to be aggressive, as UV degradation is coupled with high humidity, temperature and biological degradation (Davies and Choqueuse, 2009). Basically two kinds of degradation appear during immersion in aqueous media: Physical degradation with plasticizing effects and swelling and chemical degradation induced by matrix hydrolysis and fibre degradation (Davies and Choqueuse, 2009; Gautier et al., 1999). These mechanisms for natural fibre composites were reviewed in detail (Azwa et al., 2013).

It is well established that vegetal fibres have an affinity with water molecules due to their chemical composition and their porous structure (Hill et al., 2009). In addition to the conventional diffusion mechanism through the matrix, water can diffuse along the fibre/matrix interface thanks to capillary mechanism and through the fibre itself (Le Duigou et al., 2013; Wang et al., 2006).

Water will be able to establish intermolecular interactions (hydrogen bonding) with the fibre surface reducing adhesion between fibres and matrix (Le Duigou et al., 2013). Water sorption generally may provoke swelling of fibres especially when free volume is available (Clair, 2001). Many authors claim that differential swelling between fibre and matrix generate high levels of swelling stress causing cracking and delaminating (Azwa et al., 2013; Dhakal et al., 2007). However no information is available in the literature for flax or hemp swelling under constraint, so care is required in the interpretation of results.

During the aging process some components located on the fibre surface are washed out of the sample, which leads to interfacial debonding and change to the interfacial area (Dhakal et al., 2007; Joseph et al., 2002; Le Duigou et al., 2013). Some authors (Chen et al., 2009) claim that enzymatic degradation occurs for long term immersion even if no specific studies have been carried out. All these phenomena induce a loss of the mechanical properties and by consequence a reduction of the lifetime of vegetal fibre reinforced composites. 
Life expectancy is most often evaluated by accelerated aging tests as performed on Hemp/PLA (Islam et al., 2010), on Flax/epoxy (Scida et al., 2013) and Flax/PLA (Le Duigou et al., 2009a). Although these experiments permit time saving, a comparison with natural aging is necessary if they are to be validated.

The present article reports a study of the effect of 2 years' natural seawater aging on Flax/PLA biocomposites. Weight gain measurements were performed associated with static mechanical characterization and SEM observations. Back calculation of fibre properties was then performed by using micromechanical modeling.

Finally, cyclic tensile tests were conducted in order to identify a damage parameter $\mathrm{d}$ and to examine its kinetics due to aging (Davies et al., 2001). Mechanical characterization was carried out on wet and dried samples in order to separate reversible effects from irreversible damage.

\section{Materials and methods}

\subsection{Materials}

Flax fibres, harvested in France have been dew retted before being scutched. No chemical treatment has been added. Poly(L-lactide) (PLLA) supplied by Biomer ${ }^{\circledR}$ is used as matrix. Initial molecular weight was $220000 \mathrm{~g} / \mathrm{mol}$. Mechanical, thermal properties and ageing behaviour have been studied previously (Le Duigou et al., 2009a).

\subsection{Biocomposite manufacturing}

Injection moulding is used here to produce the large number of identical samples needed for ageing tests. For yacht manufacturing, it is certainly not the most suitable manufacturing process, and is more convenient for marine component manufacturing. However all information collected here should help to develop our knowledge on plant fibre composites for marine applications.

Flax fibres have been cut $(2 \mathrm{~mm})$ before being blended with polymer during extrusion step. PLLA pellets and flax fibres were dried under vacuum at $60 \mathrm{C}$ for $12 \mathrm{~h}$ prior to extrusion. They were then extruded with flax fibres $20 \%$ in weight which corresponds to $16 \%$ by volume. Compounding was achieved in a single screw extruder at $20 \mathrm{rpm}$ and with the following temperature profile: $175 / 180 / 185$ and $185^{\circ} \mathrm{C}$ in the nozzle. Compounded pellets were also dried under vacuum at $60 \mathrm{C}$ for $48 \mathrm{~h}$. Injection moulding was then carried out on a Battenfeld 210/80 machine. Temperature profile was kept as follows: $165 / 170 / 175 / 180$ and $180^{\circ} \mathrm{C}$ in the nozzle. Materials were injected in a mold designed to produce normalized dogbone specimens. The mould temperature was maintained at $20^{\circ} \mathrm{C}$.

\subsection{Aging conditions}

Samples were immersed in natural seawater at 5 meter depth for 2 years in Kernevel harbor (Lorient-France) where water temperature typically varies yearly from 8 to $19^{\circ} \mathrm{C}$. Natural seawater conditions are essential to provide baseline information compared to future work on accelerated ageing conditions. 
Samples were periodically removed to be weighed and characterized. Weight gain was determined as a percentage of initial weight using equation 1 :

$\Delta W=\frac{\mathrm{Wt}-\mathrm{W} 0}{\mathrm{~W} 0} x 100$

The Fickian diffusion coefficient $D$ is determined from Eq. (2) with assumptions of an uniform moisture distribution, an isotropic composites and no influence of specimen geometry.

Determination of diffusion coefficient is done in the range where the values of $\Delta W(\%)$ are less than $60 \%$ of the equilibrium value $\Delta W(\infty)$ :

$D=\pi\left(\frac{d \theta}{4 \Delta W(\infty)}\right)^{2}$

where $\theta$ is the slope of the linear part of the plot of weight gain versus square root of immersion time divided by sample thickness. Thus, a correction factor is needed to account for the finite width $w$ and length $h$ of the sample compared to its thickness, Eq.(3) (Arbelaiz et al., 2005):

$D_{c}=D\left(1+\frac{d}{h}+\frac{d}{w}\right)^{-2}$

where $D_{c}$ is the corrected diffusion coefficient. The use of a Fickian diffusion model to describe diffusion in a heterophasic medium such as a biocomposite with very substantial differences in $D$ for the two phases is questionable, and the water profiles within the composite are clearly very complex.

Biological activity (algae, microorganisms...) appearing on the sample surface (Figure 1) was systematically removed and samples were rinsed with deionized water before weighing.

To get additional gravimetric data, samples were placed in a $20 \mathrm{~L}$ metallic bucket filled with seawater which was renewed each week. Good correlation was observed between both sets of samples. Samples were air-dried until constant weight was reached. To evidence the reversible component of the water ageing (plasticization).

\subsection{Cyclic tensile behaviour : Damage analysis}

Injection-molded Flax/PLA biocomposites have anisotropic reinforcement which can be considered as randomly dispersed in-plane (Bourmaud et al., 2013). Analysis of stress-strain tensile curves allows a rough evaluation of damage thresholds (loss of linearity) corresponding to crack initiation in the areas where reinforcements are transversally oriented compared to the loading direction (Gibson, 1994a). To obtain an accurate evaluation of the damage threshold as well as damage kinetics, load-unload cycles were applied to our samples. The first loading cycle represented $5 \%$ of the maximal load during static characterization. For following cycles the load was increased by steps of $100 \mathrm{~N}$ (Figure $2 \mathrm{~A}$ ). 
The purpose of this characterization method is to evaluate residual strain due to load-unload cycles and damage appearance (Figure $2 \mathrm{~B}$ ). Similarly a damage criterion $d=1-E / E_{0}$ corresponding to the evolution of Young's modulus as a function of load-unload cycles has been used to follow the effects of glass/polyester seawater aging (Davies et al., 2001). This approach will be applied to follow damage kinetics of seawater aging of Flax/PLA biocomposites.

\subsection{Scanning Electron Microscopy (SEM)}

The fracture surfaces were analyzed by scanning electron microscopy (SEM). The samples were sputter-coated with a thin layer of gold in an Edwards Sputter Coater, and observed with a Jeol JSM 6460LV scanning electron microscope.

\section{Results and discussion}

\subsection{Water uptake}

Figure 3 shows the water uptake of the pure and 20\%-wt flax fibre reinforced PLA. The diffusive behaviour is close to Fickian with a water uptake at saturation after an immersion time around one month and half.

The PLA weight uptake is quite low $(0.77 \%)$ with a diffusion coefficient of $2.010^{-6} \mathrm{~mm}^{2} / \mathrm{s}$. Nevertheless, these results correlated well with published values (Deroiné et al.; Yew et al., 2005). The incorporation of flax fibres into the PLA matrix clearly leads to an increase in the water uptake and the water diffusion coefficient $D_{c}$; they reach plateau values, after 2 months, of $3.3 \%$ and $1.310^{-4} \mathrm{~mm}^{2} / \mathrm{s}$, respectively. These values are higher than those obtained on infused epoxy/glass composites used for underwater application (Boisseau, 2011) immersed in filtered seawater at 4 and $20^{\circ} \mathrm{C}$, but much lower than those obtained on unprotected wood (around 20\%) used in yacht building for many years (Glass and Zelinka). Ways of reducing the seawater uptake of PLA/Flax biocomposites have been described elsewhere (Le Duigou et al., 2011).

By using simple scale transition model, it is possible to estimate water uptake of flax fibres knowing those of polymer and composite (Figure 3) (Halpin and Kardos, 1976). For that, composite porosity level is assumed to be negligible.

$\Delta \mathrm{W}$ composite $=\Delta \mathrm{W}_{\text {fibre }} \mathrm{X}$ fibre content $+\Delta \mathrm{W}_{\text {matrix }} \times(1-$ fibre content $)$

Where $\Delta \mathrm{W}$ is the water uptake.

In this case, the saturation weight value is around $12 \%$ for the flax fibres which is clearly higher than the biocomposite or matrix values. These values are close to those obtained by Dynamic Vapour Sorption (DVS) (Hill et al., 2009; Stamboulis et al., 2001) and gravimetric methods (Celinot et al., 2013).

This important weight uptake could be explained by the chemical constitution of the fibre as well as the multilayer structure with primary and secondary cell-wall (Baley et al., 2014). The main components of this primary wall are pectins (Cosgrove, 2005)), hemicelluloses, low crystalline 
cellulose (Zykwinska et al., 2008) and waxes (Bos, 2004). Secondary cell-wall (S2) is the main structural layer, responsible for the majority of the mechanical performance and the physical properties of the fibre. Is it composed of crystalline cellulose microfibrils which are surfaced by hemicelluloses and incrusted within a pectin matrix. The hydrophilic character of the cell-wall is due to the hydroxyl groups of these various components (Zafeiropoulos et al., 2003). In this way, the methylesterification degree of the pectins, the chains size and the hemicelluloses polymerization rate, as well as the cellulose crystallinity rate, influence the water accessibility (Davies and Bruce, 1998; Morvan et al., 2003; Zykwinska et al., 2008). Some authors (Hill et al., 2009; Stamboulis et al., 2001) underline the influence of micro capillarities or lumen into the water diffusion.

\subsection{Mechanical properties and tensile behaviour after immersion}

Figure 4 shows the evolution of the tensile mechanical behaviour of the wet $(A)$ and dried $(B)$ composites as a function of the immersion time.

Biocomposites exhibit an initial brittle behaviour for unaged samples which becomes more and more ductile with the immersion time. The elastic-linear area, where the damage is irreversible, reduces as a function of the water ageing. The dissipated energy until the breakage, obtained from the area under the loading curve, increases with the water uptake. Dried biocomposites after immersion (Figure 4B) shows a partial reversibility of the unaged mechanical behaviour with a reduced ductility and higher stiffness compared to wetted counterparts. Nevertheless, from an immersion time of 15 days, the dried specimens exhibit a different behaviour compared to unaged, showing irreversible damage mechanisms.

The Young's modulus is calculated from the linear part of the stress-strain curve. This stiffness is generally evaluated from the tangent method between 0.05 and $0.25 \%$ (British Standard, 1997). Some authors, on UD composites, calculate the stiffness between 0,025 and $0.1 \%$ (Shah et al., 2012) or 0.05 and $0.1 \%$ (Baets et al., 2011).

In order to visualize this linearity loss, the Young's modulus is drawn for different deformation ranges for each immersion time (Figure 5). This shows a decrease in the composites stiffness after a $0.1 \%$ deformation, corresponding to the first biocomposite damage.

The rigidity calculation cannot be performed over this entire range. Between 0.025 and $0.1 \%$, the Young's modulus seems to increase on most of the immersed samples and especially until $0.5 \%$. This phenomenon could be due to the fibre stiffness increase (Placet et al., 2012) or to a water desorption during the tensile experiment. A plateau could be observed between 0.05 and $0.1 \%$. The Young's modulus will be determined in this area.

Figure 6 shows the properties variation (stiffness and strength at break) versus the immersion time for dried and wet specimens.

Initial specific tensile stiffness of Flax/PLA biocomposites is higher than that of glass/Polypropylene composites for similar fibre weight fractions and processing routes (Le Duigou et al., 2008), which satisfies one the two design criteria in the ISO $12215-5$ standard (ISO12215-5, 2008) for yacht design. Tensile strength is however lower than that of glass/PP, around $30 \%$ which implies that additional material will need to be used in order to achieve a similar mechanical function. Life Cycle Analysis (LCA) should answer whether or not the additional quantity of biocomposite is an environmental burden.

Immersion for around 200 days in natural seawater induces a drastic decrease of the Young's modulus and the strength at break $(-40 \%)$ followed by a stabilization immersion corresponding to the biocomposite saturation time observed using a gravimetric method (Figure 3). After stabilization, the Young's modulus and the strength at break are $4 \mathrm{GPa}$ and $32 \mathrm{MPa}$, respectively. 
The PLA/flax 30\%-wt samples, immersed for 18 months in filtered natural seawater exhibit a similar stiffness but a lower tensile strength (around $20 \mathrm{MPa}$ ). By comparison, some polyester/glass composites, immersed for 2 years in a natural marine environment, exhibit a tensile stiffness and flexural strength at break decrease of around $10 \%$ and $20 \%$, respectively (Davies and Choqueuse, 2009). An exposure to marine air at $20^{\circ} \mathrm{C}$ for 30 years was shown to induce a flexural strength at break decrease of $20 \%$ for other glass/polyester composites (Gutirrrez et al., 1992).

Figure 7 shows the evolution of the mechanical properties change according to the weight uptake. The values obtained are compared with those of PLA/flax $30 \%$-wt immersed in filtered sea water at $20^{\circ} \mathrm{C}$ and $40^{\circ} \mathrm{C}$ (Le Duigou et al., 2009b).

The evolution of the Young's modulus and the strength at break in a natural environment for the $20 \%$-wt composite exhibits the same trend as those of the 30\%-wt immersed biocomposite in filtered seawater; nevertheless, the ageing effects on the $30 \%$-wt material seems to be reduced (Le Duigou et al., 2009b). The fibre loading increases the water uptake of the biocomposite and at the same time, we can notice that the mechanical property decrease as a function of the water uptake is more pronounced for the $20 \%$-wt composites.

The specimen drying highlights the ageing reversibility; thus, for immersion times lower than 60 days, the stiffness degradation is reversible. The strength at break is more sensitive to irreversible degradation seeing that from 15 days, the property degradation is no longer reversible (Figure 6). Indeed, the composite stiffness is strongly linked to the component properties and therefore to their evolution during ageing; moreover, the Young's modulus is obtained at the beginning of the loading where the damage levels are low. The strength at break also depends on the failure properties of each component, and especially on the interactions between them, on the reinforcement's dispersion and also on the damage accumulation induced by the ageing.

\subsection{Estimation of the fibre properties evolution in the composite}

It is possible to estimate the biocomposite Young's modulus from the components properties and the reinforcement morphology by using Halpin-Tsai model to fit experimental data (Le Duigou et al., 2008). The following data have been used to estimate the composite stiffness: For fibres : $E_{\mathrm{fL}}=53.8 \pm 14.3 \mathrm{GPa}$ (Bourmaud et al., 2013) and $E_{\mathrm{fT}}=7 \pm 2 \mathrm{GPa}$ (Baley et al., 2006), the anisotropy ratio $\left(E_{T} / E_{L}\right)$ is 0.13 . For polymer, Young modulus of the PLLA matrix is $3620 \pm 67 \mathrm{MPa}$. The longitudinal modulus $\mathrm{E}_{\mathrm{L}}$ and the transverse modulus $\mathrm{E}_{\mathrm{T}}$ for a ply reinforced by short unidirectional fibres is given by equations (6) and (7):

$$
\frac{\mathrm{M}}{\mathrm{M}_{\mathrm{m}}}=\frac{1+\xi \cdot \eta \cdot \mathrm{V}_{\mathrm{f}}}{1-\eta \cdot \mathrm{V}_{\mathrm{f}}}
$$

$$
\eta=\frac{\frac{M_{f}}{M_{n}}-1}{\frac{M_{f}}{M_{m}}+\xi}
$$

where $M=E_{L}$ or $E_{T}, M f=E_{f l}$ or $E_{f t}$ and $m, f, I$ and $t$ correspond to matrix, fibre, longitudinal and transversal. $V_{f}$ is the fibre volume fraction and $\xi$ the form factor. For the longitudinal modulus, $\xi=2$ $\mathrm{L} / \mathrm{d}$ where $\mathrm{L} / \mathrm{d}$ is the fibre aspect ratio. For the transverse modulus $E_{t}$, satisfactory results have been obtained with $\xi=2$ (Gibson, 1994b). The modulus of a ply reinforced by randomly dispersed fibres is given by the following expression (Gibson, 1994b): 


$$
E_{\text {mat }}=\frac{3}{8} E_{L}+\frac{5}{8} E_{T}
$$

where $E_{L}$ is the longitudinal modulus and $E_{T}$ the transverse modulus of the unidirectional ply.

The stiffness of the biocomposite is $6105 \mathrm{MPa}$ against $6395 \pm 175 \mathrm{MPa}$ which could be considered as a correct estimation with an error around 5\%. From the evolution of the biocomposite Young's modulus with the immersion time, it is possible to estimate the evolution of the transverse and longitudinal flax fibre moduli.

The evolution of the PLA Young modulus is assumed to be negligible after immersion (Le Duigou et al., 2009a) as well as the anisotropy ratio of flax fibres. Moreover, the fibre matrix adherence is assumed to be constant during the immersion time. Figure 8 shows the evolution of the fibre transverse and longitudinal moduli estimated with the biocomposites immersion time.

The Halpin-Tsai estimations indicate a large decrease in the longitudinal and transverse fibre properties with the immersion time and stabilization around 200 days. After drying, the biocomposite recovers its initial properties until around 90 days, showing a plasticizing effect of the cell walls. This phenomenon has previously been shown on wood fibres mixed with a PLA matrix (Almgrem, 2010). This tendency could explain the mechanical results obtained on immersed specimens.

The definitive loss of the fibres properties may be due to the washing out of soluble components ensuring the mechanical integrity of the fibres.

\subsection{Evolution of the biocomposite damage process}

Figure 9.A shows the evolution of the biocomposite cycling behaviour before and after a 710 days marine environment immersion. From the curves and imposed cycles, it is possible to show the evolution of a damage criterion $d$ as a function of the immersion time (Figure 9.B).

The damage criterion increases more and more with the deformation and the immersion time. An increase of the damage criterion from a $0.3 \%$ deformation for the 60 days immersed samples compared to $0.6 \%$ for the virgin biocomposites is observed. For the 180 to 710 days immersed samples, the $d$ increase appears at the very low strains indicating an early damage threshold.

Next, the damage criterion $d$ increases more quickly on the short immersed samples revealing high damage kinetics. When the strain increases, a loss of linearity between $d$ and the strain appears, probably due to the desorption phenomenon, especially for long immersion times (between 180 and 710 days).

On this kind of specimens with randomly dispersed fibres, the first irreversible damage occurs in the transversely loaded areas (Baley et al., 2006; Bourmaud et al., 2013). Figure 10 shows SEM images of the fracture surfaces of non-immersed biocomposites.

The non-immersed biocomposites exhibit complex damage after tensile tests. First, we notice a brittle break of the matrix well correlated with the Figure 4 observations. Then, the interfacial breaks (red arrow) are present between the matrix and the transverse orientated fibre bundles $(y-x$ plane). 
These fibres bundles, originated form natural structure within the plant, could be considered as favoured breakage areas due to the heterogeneity of the surrounding stress (Baley et al., 2006).

Finally, some flow oriented fibre breakages are seen with low debonding length, indicating important interface interactions between the flax and the PLA matrix (le Duigou et al., 2012a). Moreover, cohesive breakages can be observed (red arrow on the right).

After an immersion of 2 years, the failure behaviour of the matrix changes. In addition to the fibres plasticizing, the PLA breakage becomes ductile as highlighted by Figure 11.A. these phenomena could explain the mechanical behaviour of the immersed biocomposites (Figure 4.A). After ageing, some fibre breakages are still present with long debonding lengths, compared to non-immersed samples. Nevertheless, as shown on Figure 11.A, some fibre breakages with low debonding (red arrows) could be identified, showing the efficiency of the interfacial stress transfer; moreover, fibre peeling remains (Figure 11.B). The presence of water induces a fibre bundles division (Figure 11.C), inducing a decrease of the stress transfer and then an early damage of the biocomposite as shown on Figure 9.B. Indeed, Bourmaud et al. (Bourmaud et al., 2010) have shown that a $72 \mathrm{~h}$ soft water treatment could facilitate the elementary flax fibre extraction by degrading the middle lamella pectins.

According to Figure 3, the water uptake of the flax fibre after immersion is around $12 \%$; this phenomenon should result in swelling of the cell walls. The flax fibre swelling is anisotropic with axial and transverse components around $0.05 \%$ and $20-25 \%$, respectively (Mussig et al., 2010). Little information is available on the bundle structure influence nor of the role of the matrix on the fibre properties (residual stresses).

From published papers recently summarized (Azwa et al., 2013), the fibre swelling induces cracking and overstress in the surrounding matrix. Nevertheless, the SEM observation on elementary fibres does not enable this kind of damage to be clearly identified. In the same way as for wood (Virtaa et al., 2006), the flax fibre swelling under stress could induce a relaxation phenomenon. Some holes are observed, mainly around the fibre bundles, explaining the nonreversibility of the damage. As underlined in the literature (Almgren et al., 2009), the swelling of plant fibre composites depends on the consolidation and on the available free volume fraction. Thus, the lack of cohesion and the swelling should be favoured by the presence of fibre bundles (Figure 11.D). Moreover, the surface components dissolution could influence the interfacial debonding.

\section{Conclusion}

Innovation in sailing yacht design must include current environmental concerns such as resource depletion and waste management. For this reason it is important to examine biocomposites based on plant fibre reinforced biopolymers, $100 \%$ recyclable and compostable. They offer high specific stiffness and low environmental footprint, but their marine ageing mechanisms are not yet well understood.

The present article has given information on 2 years natural seawater aging of injection-molded flax/PLA biocomposites.

Biocomposites suffer from relatively high moisture absorption which is controlled by the vegetal fibres. However, comparable values can be found for wood which has been used for centuries in boat manufacturing.

A simple rule of mixtures allows the determination of a weight gain at saturation for flax fibres of around $12 \%$ which is close to published values. Bundles of fibres and especially middle lamellae 
influence water uptake. Water alters biocomposites and flax fibres since their mechanical properties are reduced (Young's modulus and tensile strength) with aging. A linear relationship is observed between water uptake and loss of mechanical properties. Load-unload cycles have been used to highlight early damage appearance as biocomposites undergo aging. This damage can be induced by fibre bundles division which may be due to washing out of soluble components and by debonding of fibre bundles.

\section{Acknowledgements}

Authors wish to acknowledge ADEME (French Environment and Energy Management agency) for financial support.

\section{References}

Almgrem, K., 2010. Wood-fibre composites: Stress transfer and hygroexpansion. Thesis reportKTH Fibre and Polymer Technology School of Chemical Sciences and Engineering Royal Institute of Technology - SE-100 44 Stockholm Sweden.

Almgren, K., Gamstedt, E.K., Berthold, F., Lindström, M., 2009. Moisture uptake and hygroexpansion of wood fiber composite materials with polylactide and polypropylene matrix materials. Polymer composites 30 (12), 1809-1816.

Arbelaiz, A., Fernández, B., Ramos, J.A., Retegi, A., Llano-Ponte, R., Mondragon, I., 2005. Mechanical properties of short flax fibre bundle/polypropylene composites: Influence of matrix/fibre modification, fibre content, water uptake and recycling. Composites Science and Technology 65 (10), 1582-1592.

Azwa, Z.N., Yousif, B.F., Manalo, A.C., Karunasena, W., 2013. A review on the degradability of polymeric composites based on natural fibres. Materials \& Design 47 (0), 424-442.

Baets, J., Plastria, D., Ivens, J., Verpoest, I., 2011. Determination of the optimal flax fibre preparation for use in UD-Epoxy composites. $18 \mathrm{TH}$ International Conference on Composite Materials.

Baley, C., Le Duigou, A., Bourmaud, A., Davies, P., Nardin, M., Morvan, C., 2014. Reinforcement of polymers by flax fibres: The role of interfaces. . Chapter 7. Biobased composite for high performance material. From strategy to industrial application- - Editors: R Chollakup, W Smitthipong and M Nardin, ISBN: 978-1-4822-1448-2.

Baley, C., Perrot, Y., Busnel, F., Guezenoc, H., Davies, P., 2006. Transverse tensile behaviour of unidirectional plies reinforced with flax fibres. Materials Letters 60 (24), 2984-2987.

Bodros, E., Pillin, I., Montrelay, N., Baley, C., 2007. Could biopolymers reinforced by randomly scattered flax fibre be used in structural applications? Composites Science and Technology 67 (34), 462-470.

Boisseau, A., 2011. Etude de la tenue à long terme de matériaux composites immergés pour structures de récupération d'énergies marines. Thesis report (In french). 
Boniou, A., Trémaré, R., 2006. Les bateaux de plaisance. Cap sur la croissance. Le 4 pages des statistiques indutrielles pour le Ministère de l'Économie, des Finances et de l'Emploi. . http://www.insee.fr/sessi/4pages/214/principal.htm, 214.

Bos, H.L., 2004. The potential of flax fibres as reinforcement for composite materials-Thesis report. Eindhoven.

Bourmaud, A., Ausias, G., Lebrun, G., Tachon, M.L., Baley, C., 2013. Observation of the structure of a composite polypropylene/flax and damage mechanisms under stress. Industrial Crops and Products 43 (0), 225-236.

Bourmaud, A., Morvan, C., Baley, C., 2010. Importance of fiber preparation to optimize the surface and mechanical properties of unitary flax fiber. Industrial crops and Products 32 (3), 662-667.

British Standard, B.E.I., 1997. Plastics-Determination of Tensile Properties-Part 4: Test Conditions for Isotropic and Orthotropic Fibre-Reinforced Plastic Composites. British Standards Institution, London (1997).

Celinot, A., Fréour, S., Jacquemin, F., Casari, P., 2013. Characterization and Modeling of the Moisture Diffusion Behavior of Natural Fibers. Journal of Applied Polymer Science DOI: 10.1002/APP.39148.

Chen, H., Miao, M., Ding, X., 2009. Influence of moisture absorption on the interfacial strength of bamboo/vinyl ester composites. Composites Part A: Applied Science and Manufacturing 40 (12), 2013-2019.

Clair, B., 2001. Etude des propriéts mécaniques et propriéts au séchage du bois à l'échelle de la paroi cellulaire: Essai de compréhension du comportement macroscopique paradoxale du bois de tension à couche gélatineuse. Report thesis- ENGREF.

Cosgrove, D., 2005. Growth of the plant cell wall. Nature reviews- Molecular cell biology 6, 850861.

Davies, G.C., Bruce, D.M., 1998. Effect of Environmental Relative Humidity and Damage on the Tensile Properties of Flax and Nettle Fibers. Textile Research Journal 68 (9), 623-629.

Davies, P., Choqueuse, D., 2009. Ageing of composite in marine vessels, in: Martin, R. (Ed.), Ageing of composites.

Davies, P., Mazeas, F., Casari, P., 2001. Sea Water Aging of Glass Reinforced Composites:Shear Behaviour and Damage Modelling. J Compos Mater 35.

Deroiné, M., Le Duigou, A., Corre, Y.-M., Le Gac, P.-Y., Davies, P., César, G., Bruzaud, S., Accelerated ageing of polylactide in aqueous environments: Comparative study between distilled water and seawater. Polymer Degradation and Stability (0).

Dhakal, H.N., Zhang, Z.Y., Richardson, M.O.W., 2007. Effect of water absorption on the mechanical properties of hemp fibre reinforced unsaturated polyester composites. Comp. Sci. Technol. 67 (7-8), 1674-1683.

Gautier, L., Mortaigne, B., Bellenger, V., 1999. Interface damage study of hydrothermally aged glass-fibre-reinforced polyester composites. Comp. Sci. Technol. 59 (16), 2329-2337.

Gibson, R., 1994a. Principle of composite materials mechanics. McGraw-Hill International Editions, New york. 
Gibson, R., 1994b. Principles of composite material mechanics. New-York McGraw-Hill.

Glass, S., Zelinka, S., Moisture Relations and Physical Properties of Wood- General Technical Report FPL- GTR Chapter 4.

Gutirrrez, J., Lelay, F., Hoarau, P., 1992. A study of ageing of glass fibre-resin composites in a marine environment. Proceedings of the International Conference on 'Nautical Construction with Composite Materials, Paris', IFREMER, p. 338.

Halpin, J., Kardos, J., 1976. The halpin-Tsai equations : A review. Polymer Engineering and Science 16, 344-356.

Hill, C., Norton, A., Newman, G., 2009. The water vapor sorption behavior of natural fbers. Journal of Applied Polymer Science 112, 1524-1537.

Islam, M.S., Pickering, K.L., Foreman, N.J., 2010. Influence of accelerated ageing on the physicomechanical properties of alkali-treated industrial hemp fibre reinforced poly(lactic acid) (PLA) composites. Polym Degrad and Stab 95 (1), 59-65.

ISO12215-5, 2008. Small craft -- Hull construction and scantlings -- Part 5: Design pressures for monohulls, design stresses, scantlings determination.

Joseph, P.V., Rabello, M.S., Mattoso, L.H.C., Joseph, K., Thomas, S., 2002. Environmental effects on the degradation behaviour of sisal fibre reinforced polypropylene composites. Comp. Sci Technol. 62 (10-11), 1357-1372.

Kumar, R., Yakubu, M.K., Anandjiwala, R.D., 2010. Biodegradation of flax fiber reinforced poly lactic acid. eXPRESS Polymer Letters 4 (7), 423-430.

le Duigou, A., Bourmaud, A., Balnois, E., Davies, P., Baley, C., 2012a. Improving the interfacial properties between flax fibres and PLLA by a water fibre treatment and drying cycle. Industrial crops and Products $39(0), 31-39$.

Le Duigou, A., Davies, P., Baley, C., 2009a. Seawater ageing of Flax/PLLA biocomposites. Polym Degrad and Stab 94 (1151-62).

Le Duigou, A., Davies, P., Baley, C., 2009b. Seawater aging of Flax/PLLA biocomposite. Polymer Degradation and Stability $94,1151-1162$.

Le Duigou, A., Davies, P., Baley, C., 2010. Macroscopic analysis of interfacial properties of flax/PLLA biocomposites. Composites Science and Technology 70 (11), 1612-1620.

Le Duigou, A., Davies , P., Baley, C., 2012b. Replacement of glass/unsaturated polyester composites by flax/PLLA biocomposites : Is it justified ? J. biobased mater. bioenerg. 5 (4), 466482.

Le Duigou, A., Davies, P., Baley, C., 2013. Exploring durability of interfaces in flax fibre/epoxy micro-composites. Composites Part A: Applied Science and Manufacturing 48, 121-128.

Le Duigou, A., Deux, J., Davies, P., Baley, C., 2011. Protection of Flax/PLLA Biocomposites from Seawater Ageing by External Layers of PLLA. International Journal of Polymer Science 2012.

Le Duigou, A., Pillin, I., Bourmaud, A., Davies, P., Baley, C., 2008. Effect of recycling on mechanical behaviour of biocompostable flax/poly(l-lactide) composites. Composite Part A 39 (9), 1471-1478. 
Morvan, C., Andème-Onzighi, C., Girault, R., Himmelsbach, D.S., Driouich, A., Akin, D.E., 2003. Building flax fibres: more than one brick in the walls. Plant Physiology and Biochemistry 41 (11-12), 935-944.

Mussig, J., Fisher, H., Graupner, N., FDrieling, A., 2010. Testing methods for measuring physical and mechancial fibre properties (plant and animal fibres). Industrial application of natural fibres : Strcture, properties and technical application- Chichester, United Kingdom, John Wiley \& Sons, 269-309.

Oksman, K., Skrifvars, M., Selin, J.-F., 2003. Natural fibres as reinforcement in polylactic acid (PLA) composites. Composites Science and Technology 63 (9), 1317-1324.

Placet, V., Cissé, O., Boubakar, M., 2012. Influence of environmental relative humidity on the tensile and rotational behaviour of hemp fibres. Journal of Material Science 47 (3435-3446).

Plackett, D., AT., L., PW., B., Nielsen, L., 2003. Biodegradable composites based on polylactide and jute fibres. Composites Science and Technology 63 (9), 1287-1296.

Roussière, F., Baley, C., Godart, G., Burr, D., 2011. Compressive and Tensile Behaviours of PLLA Matrix Composites Reinforced with Randomly Dispersed Flax Fibres. Applied composite Material, $1-18$.

Roux, A., Paris Show focuses on Environmental Protection, Scuttlebutt Europe \#1376 - 4 December [2007] accessed at 15:42 on 5 April 2008.

Scida, D., Assarar, M., Poilâne, C., Ayad, R., 2013. Influence of hygrothermal ageing on the damage mechanisms of flax-fibre reinforced epoxy composite. Composites Part B: Engineering 48 (0), 51-58.

Shah, D.U., Schubel, P.J., Clifford, M.J., Licence, P., 2012. The tensile behavior of off-axis loaded plant fiber composites: An insight on the nonlinear stress-strain response. Polymer Composites 33 (9), 1494-1504.

Stamboulis, A., Baillie, C.A., Peijs, T., 2001. Effects of environmental conditions on mechanical and physical properties of flax fibers. Composites Part A: Applied Science and Manufacturing 32 (8), 1105-1115.

Virtaa, J., Koponenb, S., Absetza, I., 2006. Measurement of swelling stresses in spruce (Picea abies) samples. Building and Environment 41, 1014-1018.

Wang, W., Sain, M., Coope, P.A., 2006. Study of moisture absorption in natural fiber plastic composites. Composites Science and Technology 66, 379-386.

Yew, G.H., Mohd Yusof, A.M., Mohd Ishak, Z.A., Ishiaku, U.S., 2005. Water absorption and enzymatic degradation of poly(lactic acid)/rice starch composites. Polym Degrad and Stab 90 (3), 488-500.

Zafeiropoulos, N.E., Vickers, P., Baillie, C., Watts, J., 2003. An experimental investigation of modified and unmodified flax fibres with XPS, ToF-SIMS ans ATR-FTIR. Joural of Materials Science 38, 3903-3914.

Zykwinska, A., Thibault, J.-F., Ralet, M.-C., 2008. Competitive binding of pectin and xyloglucan with primary cell wall cellulose. Carbohydrate Polymers 74 (4), 957-961. 


\section{Figures}

Figure 1. Biological development on the surface of Flax/PLA biocomposite

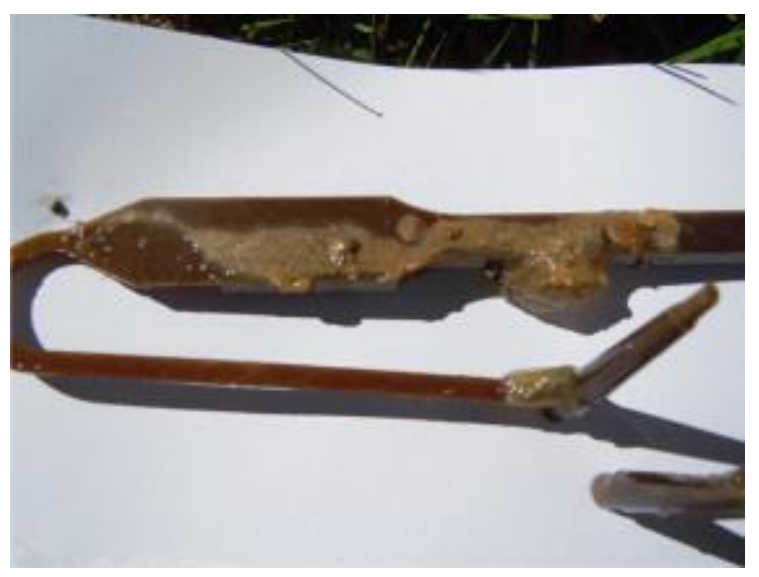

Figure 2. A Example of load-unload cycles- B Example strain evolution as a function of load-unload cycles

A

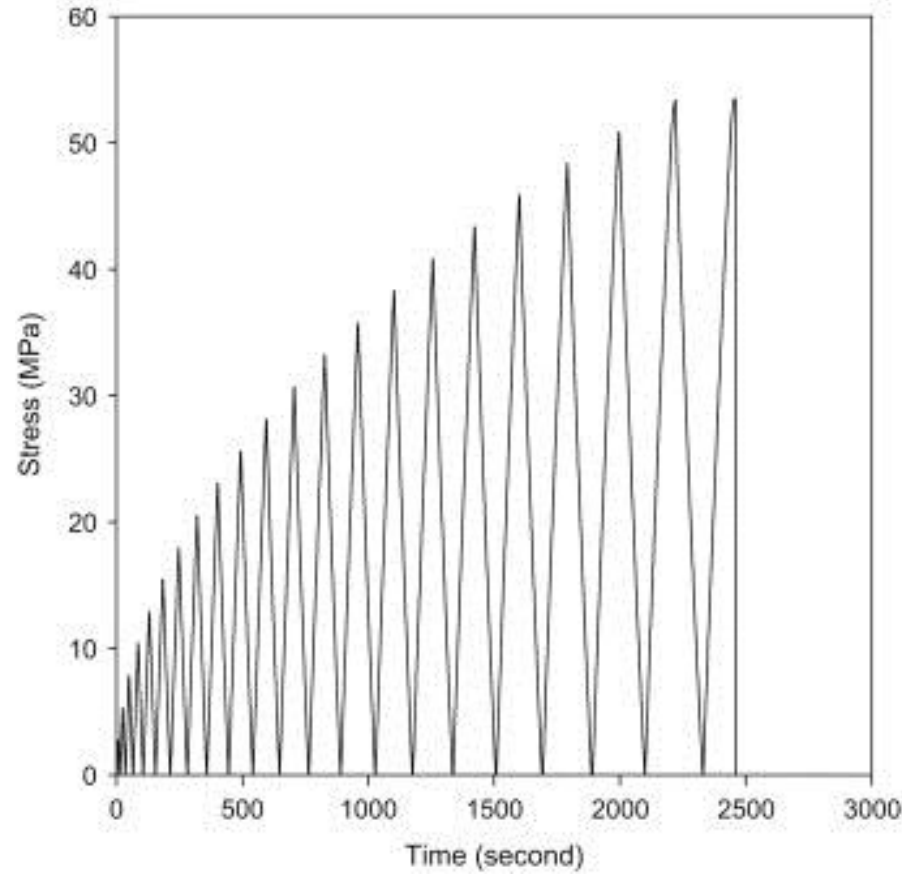

B

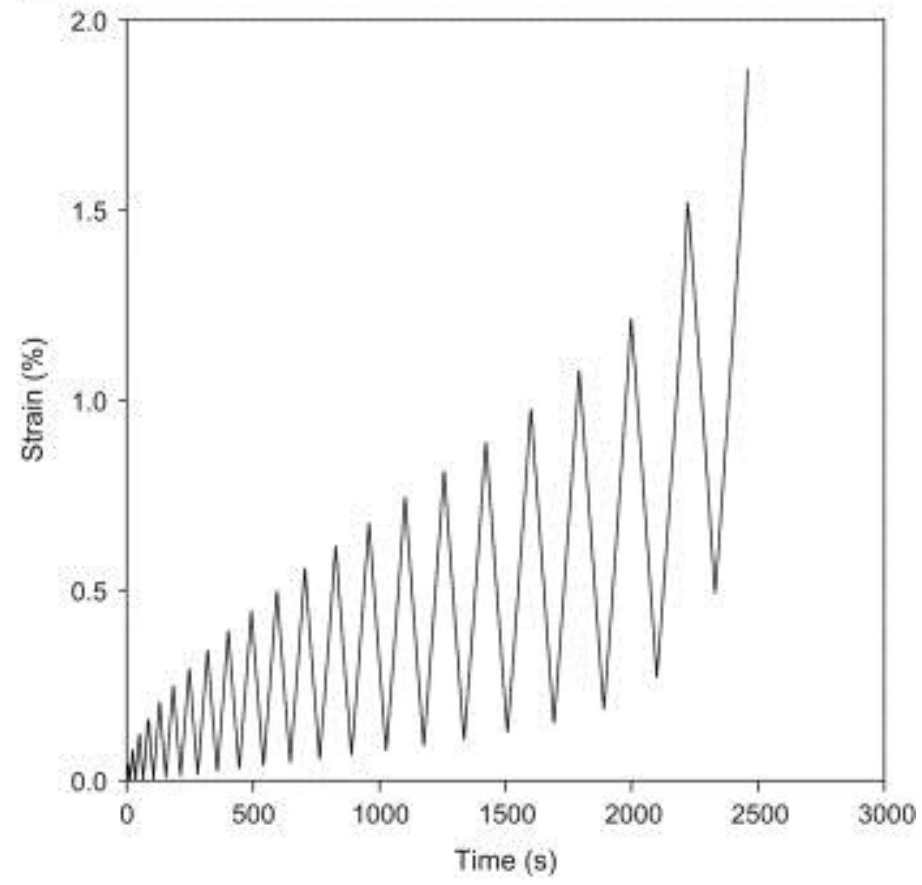


Figure 3. Water uptake behaviour of pure PLA, biocomposite and fibre (estimated)

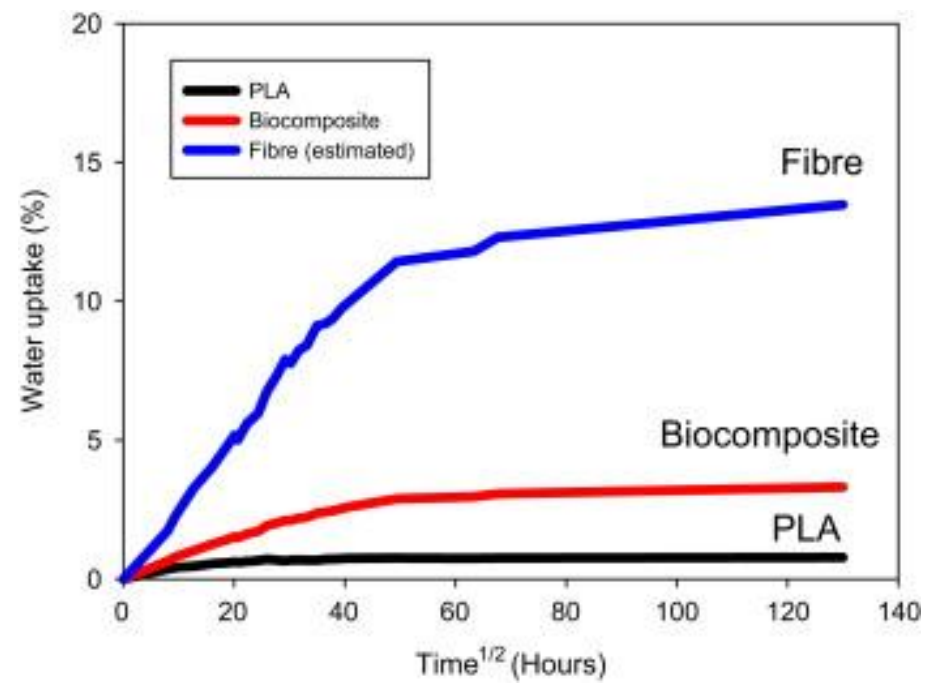

Figure 4. Stress-strain curve for biocomposite as a function of immersion time- A Wet state, B Dry state

A

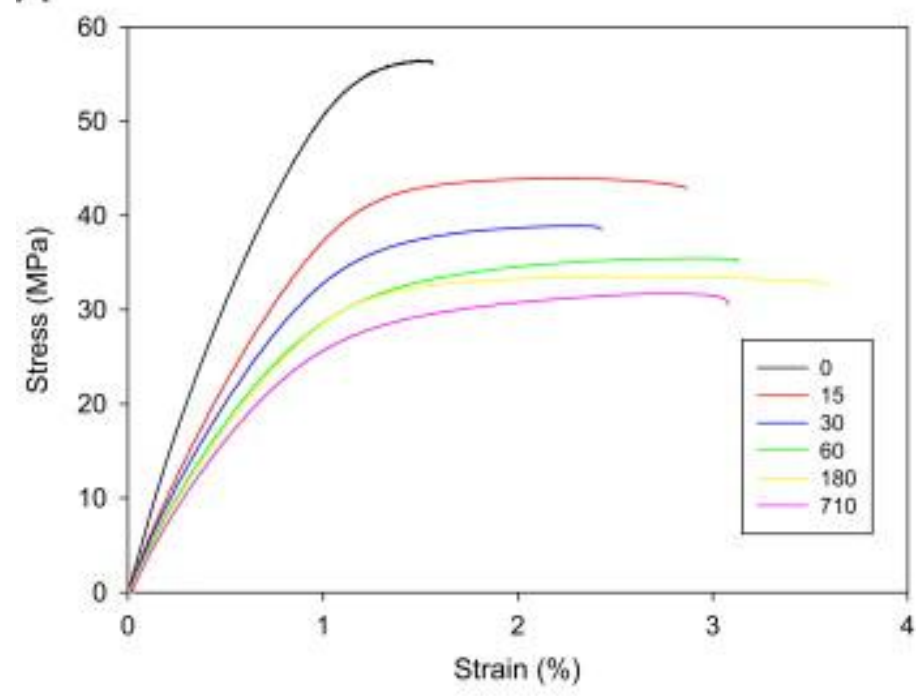

B

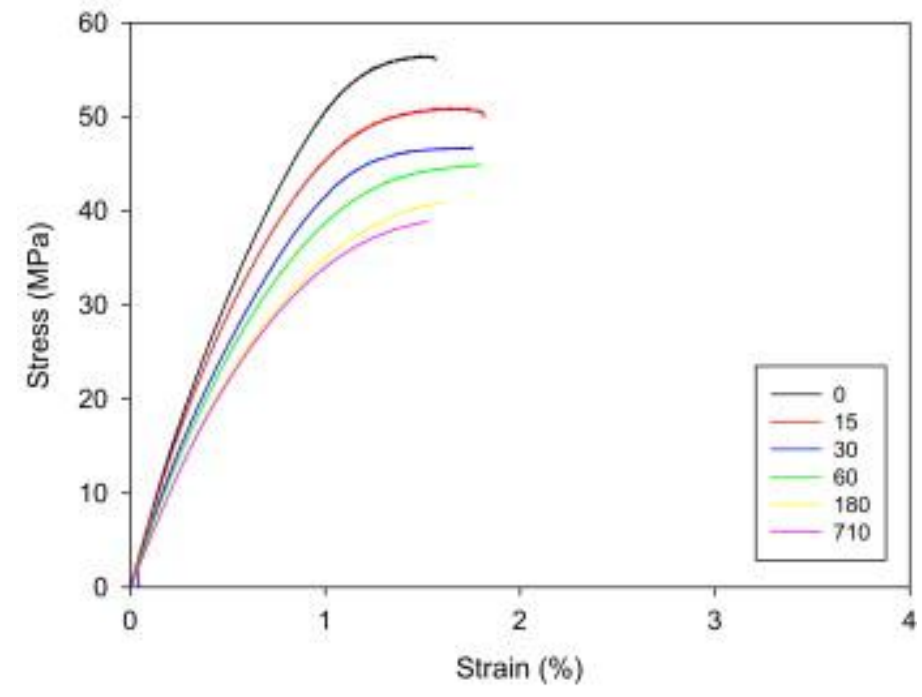


Figure 5. Young modulus vs strain curve for different strain boundary: $0.05-0.25 \%$ (A); $0.025-0.1 \%$ (B) and 0.05-0.1 (C).

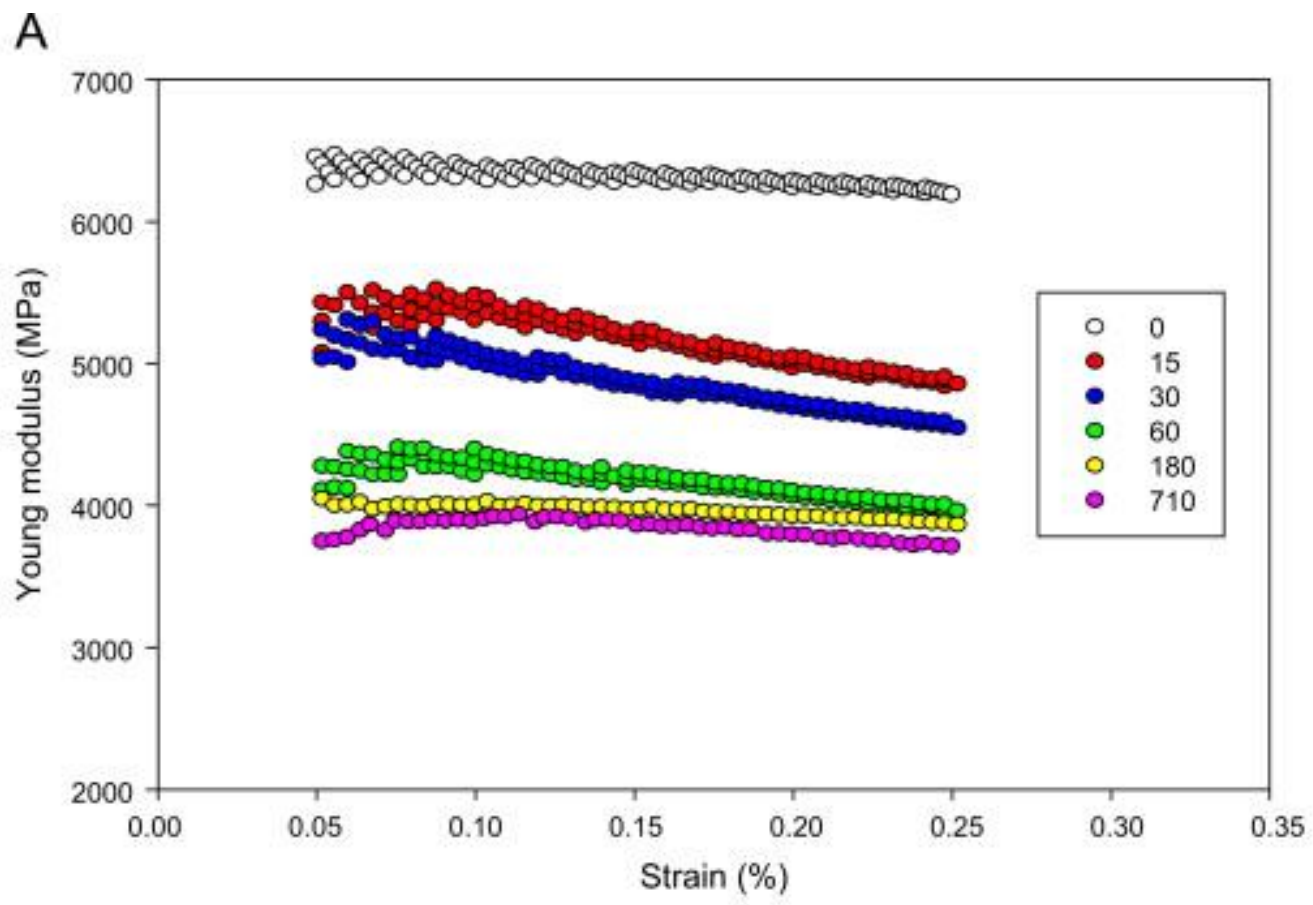

B

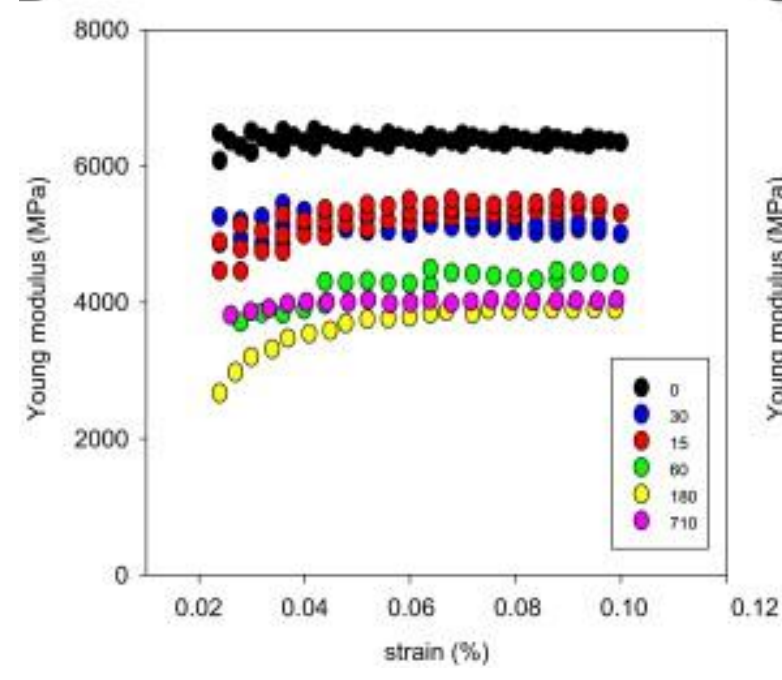

C

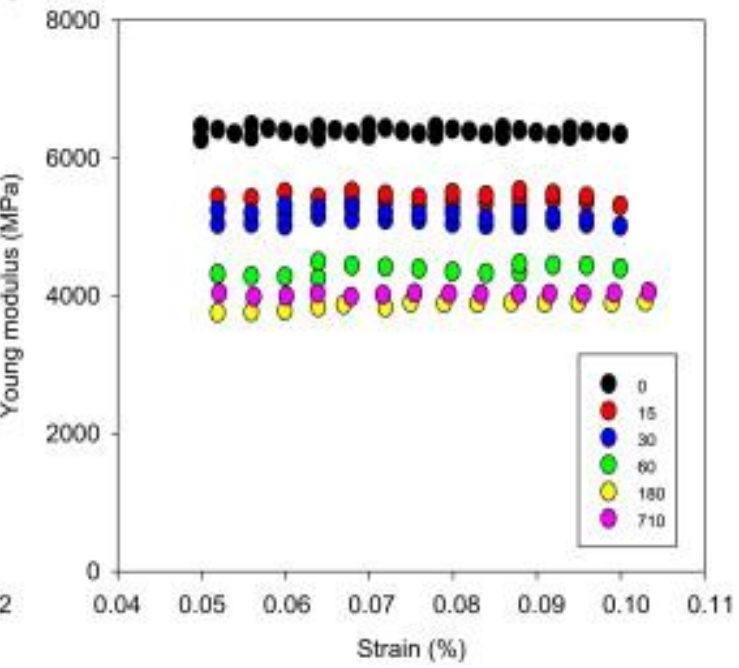


Figure 6. \% property change as a function of immersion time- Wet modulus (black symbol); wet strength (red symbol; dried modulus (empty black symbol); dried strength (empty red symbol).

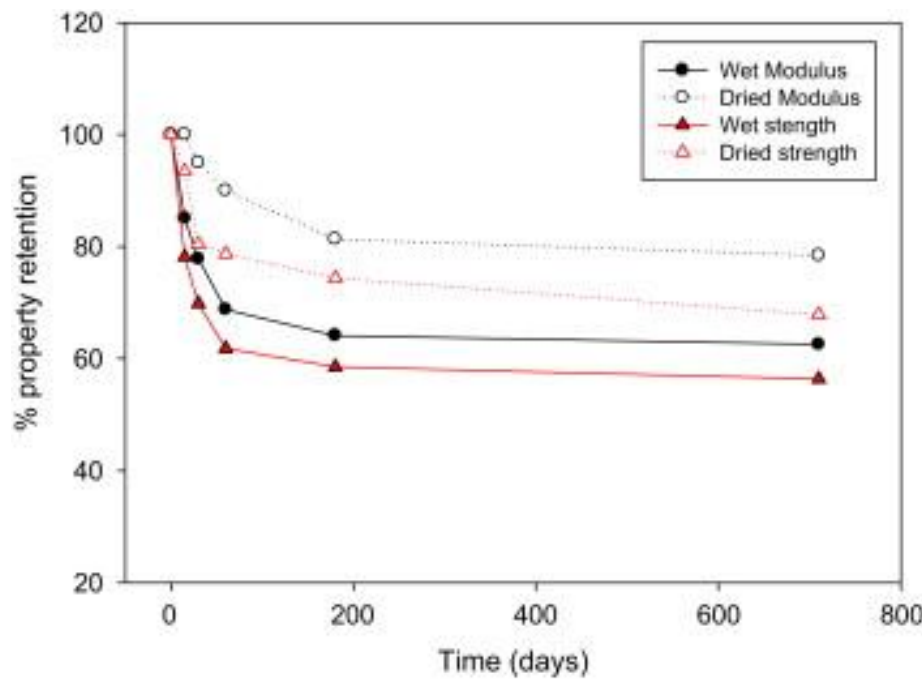

Figure 7. Property change (Young modulus and strength) of $\mathrm{BC}-20 \%$ in natural seawater and $\mathrm{BC}$ $30 \%$ (from Le Duigou et al 2009a) in filtered seawater as a function of water uptake.

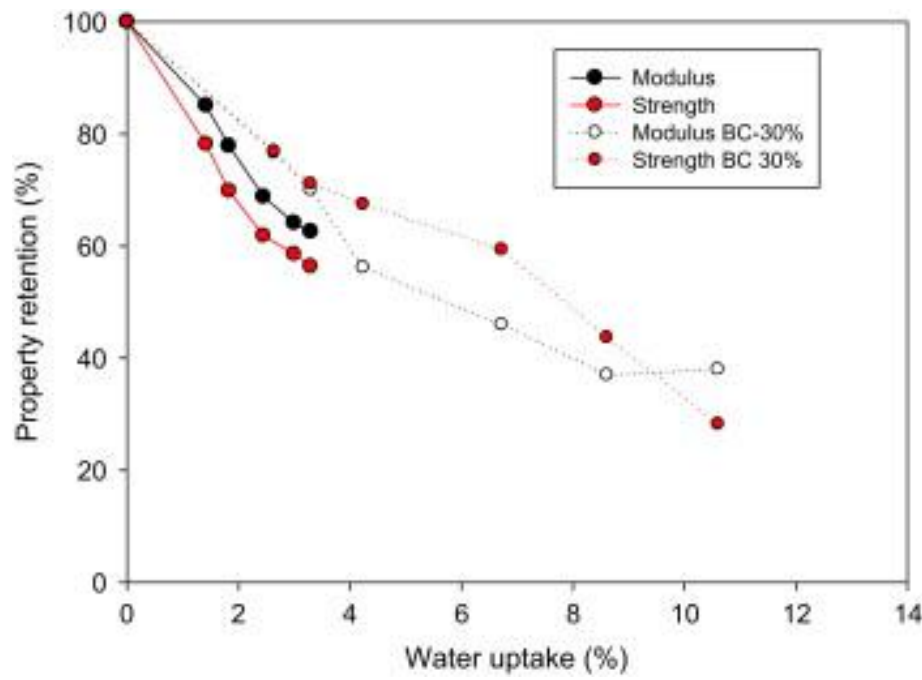


Figure 8. Evolution of the fibre longitudinal and transverse moduli estimated by using the Halpin Tsai equations.

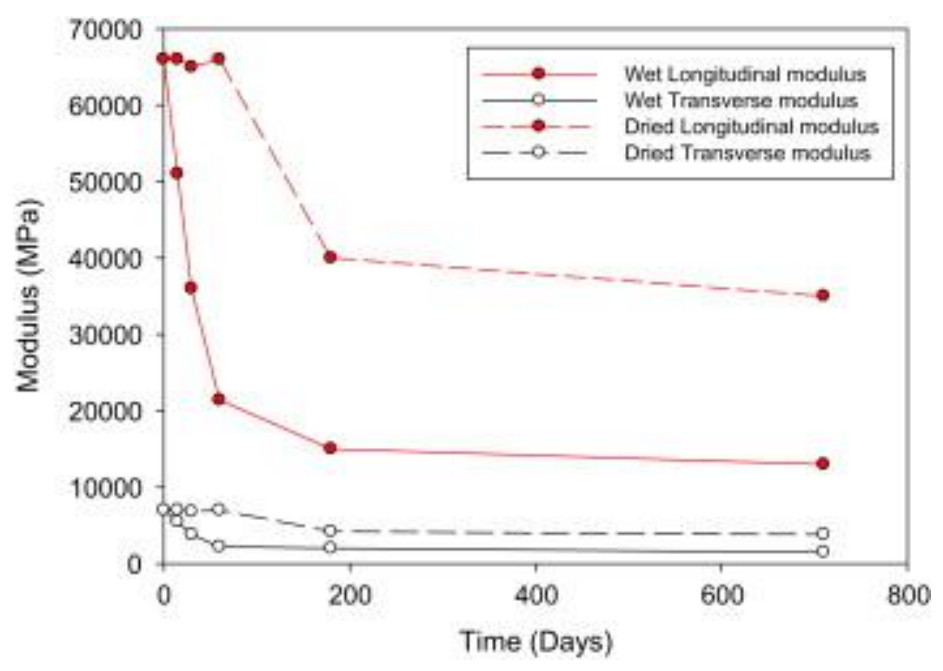

Figure 9. Cycling behavior of virgin and 710 days immersed specimens $(A)$ and evolution of the damage criterion as a function of the deformation for several immersion times (B).

A

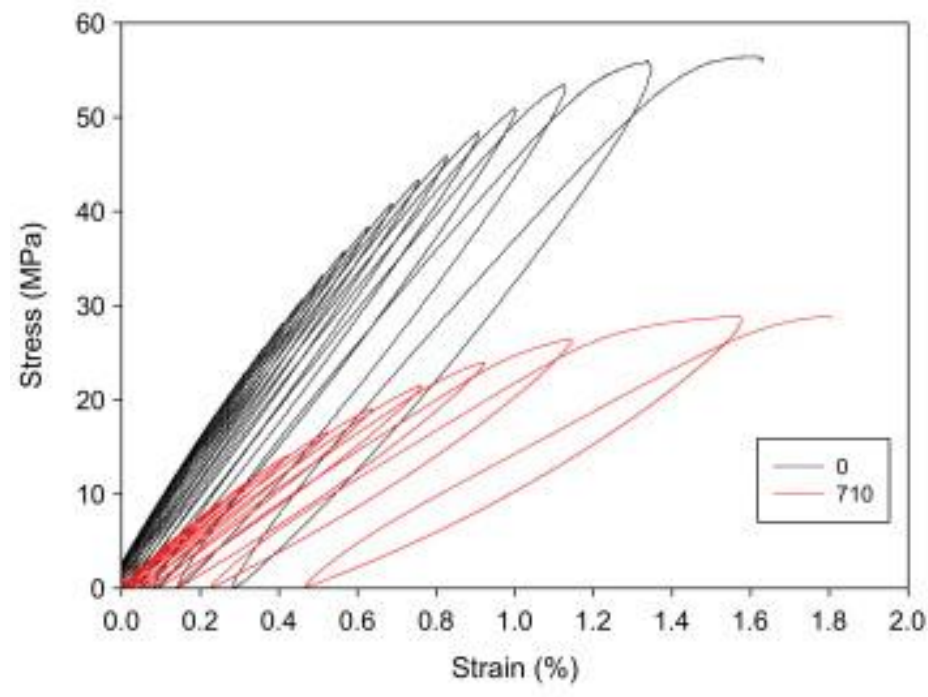

B

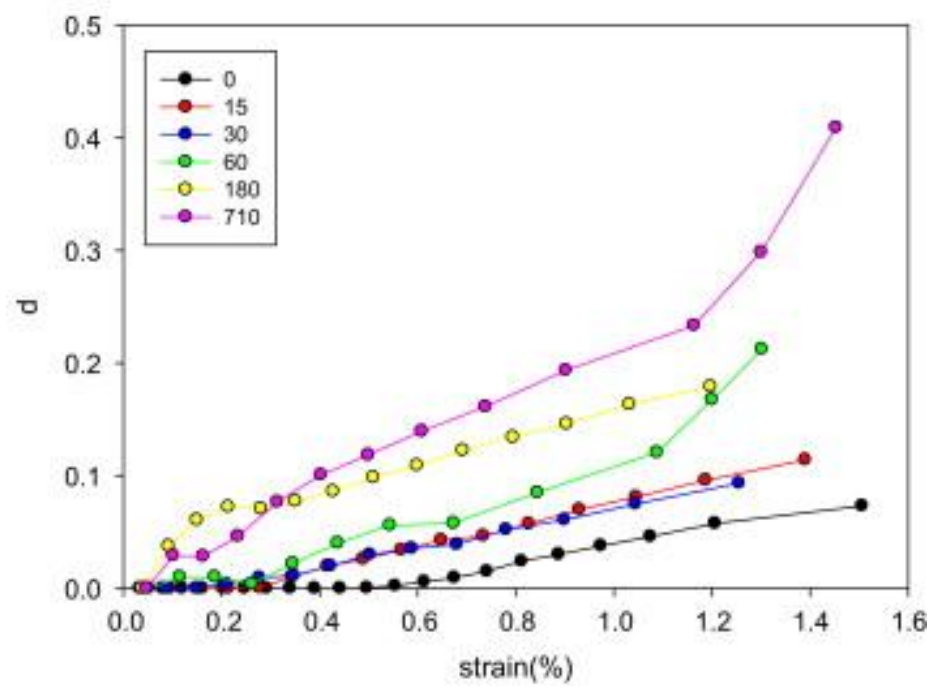


Figure 10. SEM micrographs of virgin biocomposites. $X$ is the direction of the tensile test
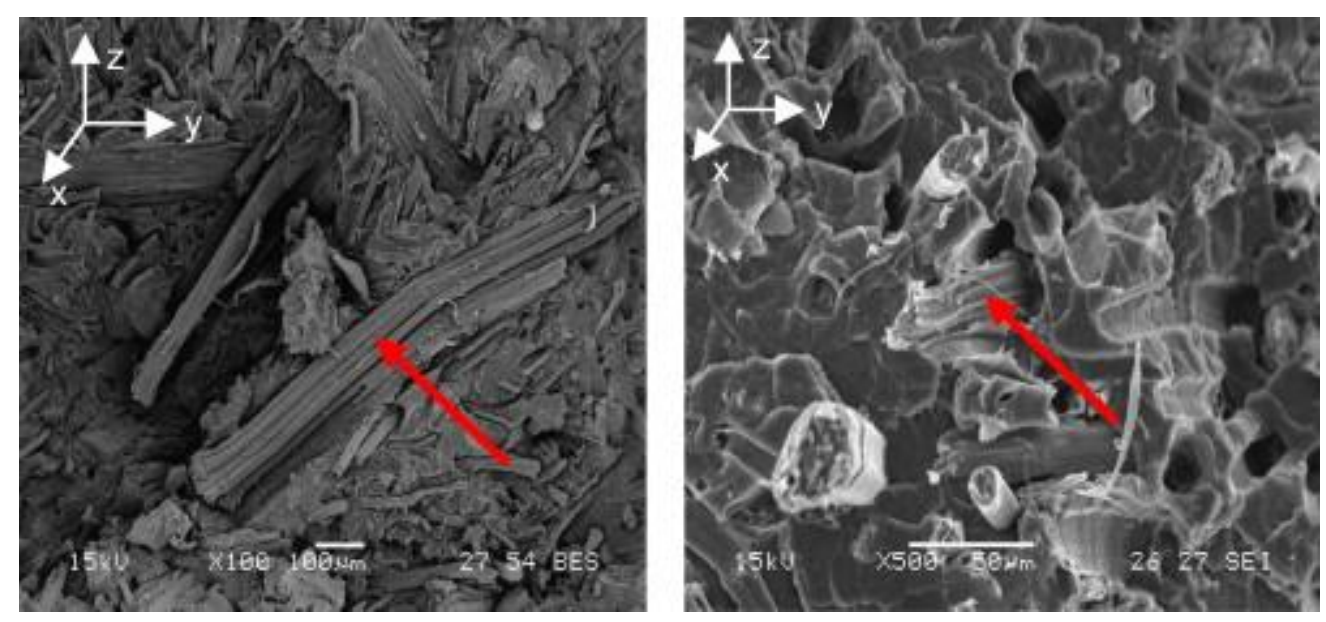

Figure 11. SEM micrographs of the 710 days immersed biocomposites fractures. $X$ is the direction of the tensile test
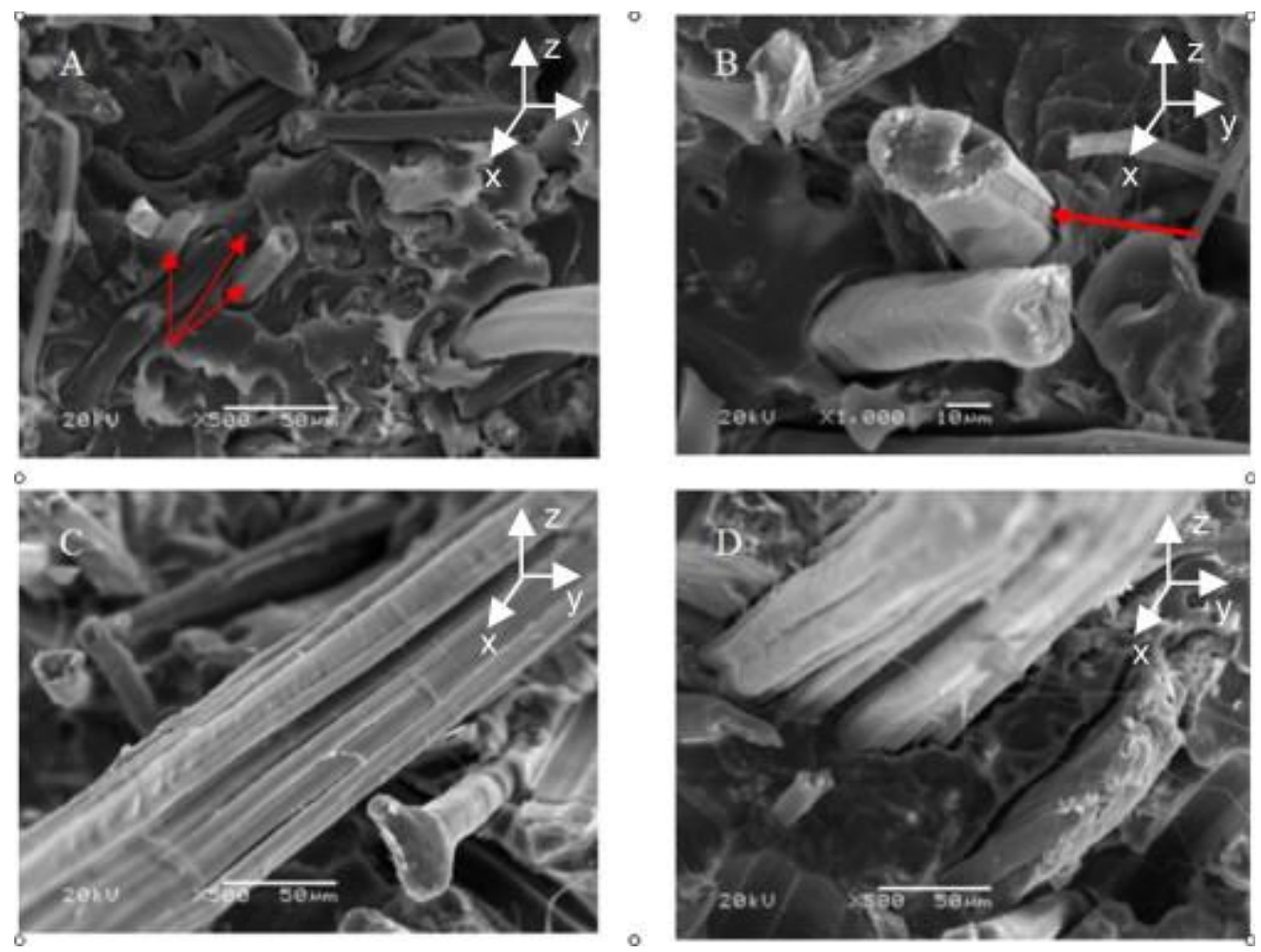